\title{
Hispanos alrededor de Augusto
}

\author{
José María BLÁzQuez MarTíNeZ † \\ Real Academia de la Historia
}

\section{RESUMEN}

Alrededor de Augusto estuvieron unos cuantos hispanos que ayudaron al emperador en la administración imperial. El presente artículo tiene como finalidad estudiar sus biografías y recoger todos los testimonios existentes sobre ellos.

Palabras clave: Hispanos. Senadores. Caballeros. Caius Iulius Hyginus. Lucius Cornelius Balbus. Aelius Marullinus. L. Decidius Saxa

\section{Hispani around Augustus}

\begin{abstract}
There were some Hispanic men who helped the emperor Augustus in the imperial administration. This paper aims to study their biographies and collect all the existing evidence on them.
\end{abstract}

Key Words: Hispani. Senators. Equites. Caius Iulius Hyginus. Lucius Cornelius Balbus. Aelius Marullinus. L. Decidius Saxa 
Caius Iulius Hyginus. La fuente principal para el conocimiento de este liberto de Augusto es el historiador Suetonio, en su libro De grammaticis et rhetoribus 20. Nació en Hispania. En el año 47 a.C. cayó prisionero de César. En Roma recibió enseñanzas de Alexander Polyhistor, célebre en aquel momento, matemático y gramático procedente de Mileto. El emperador Augusto le concedió la libertad y le colocó al frente de la Biblioteca Palatina, nombramiento que indica que le tenía por hombre culto. En Roma mantuvo amistad con algunos de los intelectuales más prestigiosos del momento, como el poeta Publius Ovidius Naso y Caius Clodius, historiador y cónsul sufecto del año 4 a.C.

Su producción literaria fue importante y variada, y gozó de aceptación, pues es citada por diferentes autores hasta varios siglos después de su muerte. Estas menciones, ordenadas por orden cronológico, son las siguientes: Columela (1.1.13) menciona dos libros; Aulo Gelio, en sus Noctes Atticae (1.14), cita De vita rebusque inlustrium virorum, y en 10.18.7 unos Exempla; Servio, en su Sobre la Eneida (3.553) recuerda De origine et situ urbium italicarum, y Macrobio, ya en la Tardo-Antigüedad, habla de él en sus Sátiras (5.18.16). Fue autor igualmente de De propietatibus deorum y dediis penatibus. Se le ha confundido con otro Hyginus, autor de unas Fábulas, pero la historiografía moderna actual no lo cree probable ${ }^{1}$.

Lucius Cornelius Balbus el Menor. Era gaditano de origen y sobrino de Lucius Cornelius Balbus, amigo de Pompeyo, que le concedió la ciudadanía, y de César, que en el año 40 a.C. le nombró senador, siendo el primer extranjero que alcanzó este honor. A. Caballos le considera senador durante el gobierno de Augusto. ${ }^{2}$ Debió de ser de origen fenicio. Como su tío, disfrutó de una gran fortuna, obtenida muy probablemente con las explotaciones mineras y con el comercio transmarino, como afirman Cicerón en sus Cartas familiares 10.32, y el historiador Tácito en sus Annales 3.72. A sus expensas cambió el urbanismo de su ciudad natal, pues construyó una nueva ciudad, la nova urbs y unos astilleros (Str. 3.2.3; 5.3), tan importantes en una ciudad dedicada fundamentalmente al comercio ultramarino. También, en el año 13 a.C. construyó un teatro en Roma, según afirmación de Plinio el Viejo (NH 36.60) y Dión Casio (54.25). Pompeyo, al final de la Guerra Sertoriana, sin duda para premiar los favores, le concedió la ciudadanía romana, en compañía de su abuelo, de su padre y de su tío, como indica Plinio ( $N H$ 5.36), que por haber sido procurador de la provincia tarraconense en época flavia estaba muy informado de sus cosas.

Participó en las principales guerras de su tiempo. Fue legado de César en el año 49-48 a.C., según escribió Cicerón en sus Cartas a Ático (8.9). En el año 48 a.C. intervino en la batalla de Dyrrachio, como recuerdan varios autores contemporáneos: Cicerón en las Cartas familiares 10.32.2; Veleyo Patérculo, 2.51.3, y el propio César en la Guerra Civil 3.19.6-7. Estuvo presente en la importante batalla de Farsalia, se-

1 Abascal 2009a, 537, con bibliografía exhaustiva, Morcillo 2003, 267-277. Sobre Pompeyo y César en Hispania, véase Novillo 2012. Sobre la Hispania de Augusto, véase MonTenegro 1982, 169-192. Recientemente está abierta al público la Casa de Augusto en el Palatino, bien conservada, donde está la biblioteca de la que fue director Hyginus (La Repubblica 14/IX/2014). Agradezco a los profesores J. M. Abascal y A. Caballos las aportaciones bibliográficas.

2 Caballos 1989, 252-254. 
gún el poeta hispano de la época de Nerón, Lucano. En el año 47 a.C. se encontraba en Alejandría, y en el año 45 a.C. en Hispania, según noticia de Cicerón en las Cartas a Ático (11.12.1). Luchó siempre en el bando de César, lo que facilitó enormemente su posterior participación en la política.

En el año 44 a.C. se encontraba en Hispania como cuestor de la Hispania Ulterior. En el año siguiente, 43 a.C., era procuestor de Annius Pollio. Cicerón, en las Cartas familiares (20.32), le acusa de que se hizo famoso por sus robos. Por entonces fue magistrado de Gades. En el año 40 a.C. fue legado propretor en su tierra y, muy probablemente en el año 32 a.C., fue cónsul. Durante los años 21-20 a.C. venció en África a los garamantes, por lo que celebró el triunfo en Roma, siendo - como puntualizan Veleyo Patérculo (1.51) y Plinio ( $N H$ 5.56) - el primer extranjero que obtuvo tan alto honor. En Roma desempeñó el alto cargo de carácter religioso de pontífice máximo. Era hombre culto, pues escribió una obra de teatro que se representó en el teatro de Gades en el año 43 a.C., como informa Cicerón en las Cartas familiares (10.32). ${ }^{3}$

La Bética dio a Roma un grupo de senadores hispanos en época de Augusto. Son los siguientes:

\section{Aelius (?) Marullinus}

De él habla la HA. Vita Hadriani 1.1-2, indicando que fue el primer senador de su familia. Se desconoce la fecha exacta de su ingreso en el Senado. Podría haber sido purgado en las lectiones del 29-28 a.C. o en las del 18 a.C., dejando el Senado él y su familia, lo que explicaría que él y su familia permanecieran en la Bética. Si su familia es la misma del emperador Hadriano, procedía de Hadria, en el Piceno, y podría pertenecer a los primeros colonos que P. Cornelio Escipión asentó en Itálica en 206 a.C., después de la batalla de Bécula antes de partir para Roma. ${ }^{4}$ A. Caballos, que ha estudiado exhaustivamente los senadores béticos, le tiene por senador en la época de Augusto, aunque pudo serlo antes.

\section{Decidius Saxa}

Debió de proceder de Celtiberia, como afirma Cicerón en sus Filípicas (11.37), entendiendo por Celtiberia una región romanizada del interior de Hispania. Era, por tanto, un celtíbero de origen, aunque muy probablemente el origen de su familia haya que buscarlo en Italia Central. La ciudadanía romana la recibió de César, y su ingreso en el Senado. Era hermano de Decidius Saxa, quien fue su cuestor en Siria. Su carrera política la debió de iniciar como centurión en el ejército de César. En el año 49 a.C. fue castrorum metallorum en la primera campaña de César en Hispania, pues era un excelente conocedor del territorio. Debió, igualmente, de participar en el año 45 a.C. en la segunda campaña contra los hijos de Pompeyo. La recompensa fue el ingreso en el Senado. En el año 44 a.C. era tribunus plebis, lo que presuponía el desempeño de la cuestura. Quizá este mismo año fue duunviro en la comisión de las divisiones de Italia.

3 Abascal 2009b, 609; Bocs 1994, 7-35; Rubio 1949, 67-119; Rubio 1950, 192-199.

4 Caballos 1989, 250-252. 
Asesinado César en los idus de marzo del 44 a.C., participó junto a su heredero, Marco Antonio, en la campaña de Mutina. En la guerra civil contra los asesinos de César intervino junto con L. Norbanus. Mandó la vanguardia de ocho legiones del ejército de los triunviros, que en el año 42 a.C. se encaminó hacia Macedonia. En el año 41 a.C. siguió a Marco Antonio después de la batalla de Filipos y fue procos provinciae Syriae. Murió poco después de la incursión de los partos en Siria, bajo el gobierno de M. Bibulus. ${ }^{5}$

\section{Decidius Saxa}

En tiempos de César ingresó en el Senado, posiblemente después de ser nombrado quaestor por el dictador. Como se ha indicado, fue procuestor de su hermano, L. Decidius Saxa, en los años 41-41 a.C. en Siria. Con Q. Labienus actuó en Apamea contra los partos. Quizás muriera durante esta campaña. No se tienen referencias posteriores de este personaje. ${ }^{6}$

En Gades, el número de caballeros era de 500 (Str. 3.5.3). Sólo Padua superaba este número y, por supuesto, Roma. Esto indica la gran riqueza de la Bética (Str. 3.2.4.6) y un comercio interno y externo grande (Str. 3.2.6). H. G. Pfaum ${ }^{7}$ ha estudiado la participación de los caballeros romanos originarios de Hispania en la administración imperial. En la administración imperial, bajo Augusto, participó C. Turranius Gracilis, que fue praefectus Aegypti del 7 al 4 a.C. Después de Augusto hasta Claudio estuvo al frente del servicio de la annona. Era como los Balbos, originariamente de Gades, según Plinio (NH 3.3).

De Hispania se conocen pocas inscripciones de comites o de adsessores de magistrados o militares romanos con este rango. Son los siguientes: Claudius, que al comienzo del gobierno de Augusto figura como comes del aerarium de Mesala, el procónsul de Asia. Se hizo cargo él solo de las cartas, de los rescriptos y de los sorteos; L. Lucius Aufidius Montanus, fue comes de Calvisius Sabinus bajo Augusto, si se trata del padre, o bajo Tiberio o Claudio, si es el hijo. El número de hispanos alrededor de Augusto no es elevado, pero desempeñaron cargos muy importantes. Eran de la absoluta confianza del emperador.

\section{Bibliografía}

Abascal, J. M.

(2009a): Caius Iulius Hyginus. [en] Diccionario biográfico español, XXVII, Madrid, 537. (2009b): Lucius Cornelius Balbus, [en] Diccionario biográfico español, XXVII, Madrid, 609.

Bocs, F. DES (1994): “L. Cornelius Balbus de Gades: la carrière méconnue d'un Espagnol à l'époque des guerres civiles. (I siècle avant J.-C.), $M C V$ 30.1, 7-35.

\footnotetext{
5 Caballos 1989, 256-258.

6 Caballos 1989, 258.

7 Pfaum 1965, 81-121.
} 
Caballos, A. (1989): “Los senadores de origen hispano durante la República Romana”, [en] J. González (ed.), Estudios sobre Urso, Colonia Iulia Genitiva, Sevilla, 252-254.

Montenegro, A. (1982): “Augusto en Hispania y en las Guerras Cántabras”, Historia de España. España Romana. II.1, Madrid, 169-192.

Morcillo, G. (2003): “Caius Iulius Hyginus, mitógrafo", Anuario de Estudios Filológicos 26, 267-277.

Novillo, M. A. (2012): César y Pompeyo en Hispania. Territorio de ensayos jurídico-administrativos en la tarda República Romana, Madrid.

Pfaum, H. G. (1965): "Le part prise par les chevaliers romains originaires d'Espagne à l'administration impériale", [en] Les empereurs romains d'Espagne. Actes du Colloque international: Madrid-Italica 31 mars - 6 avril 1964, Paris, 81-121.

RuBIO, L.

(1949): “Los Balbos y el Imperio Romano", Anales de Historia Antigua y Medieval (Buenos Aires), 67-119.

(1950): "Los Balbos y el Imperio Romano", Anales de Historia Antigua y Medieval (Buenos Aires), 142-199. 